\title{
Do Changes in Innate Immunity Underlie the Cardiovascular Benefits of Exercise?
}

\author{
Phillip Chuong, Marcin Wysoczynski and Jason Hellmann* \\ Division of Cardiovascular Medicine, Diabetes and Obesity Center, University of Louisville School of Medicine, Louisville, KY, \\ United States
}

Keywords: exercise, innate immnuity, cardiovascular disease, inflammation, physical activity

\section{INTRODUCTION}

It is well established that exercise promotes health and reduces the development and progression of cardiovascular disease (CVD) (1). Traditional risk factors for CVD, such as dyslipidemia, hypertension, and diabetes mellitus, as well as all-cause mortality, are inversely correlated with cardiorespiratory fitness (2). With advancing technology and decreasing global trends in physical activity, physical inactivity is now the fourth leading cause of death worldwide (3). Furthermore, 3 million deaths per year and an estimated $\$ 53.8$ billion in economic costs are lost due to insufficient physical activity (4). Although exercise promotes numerous salutary effects on the cardiovascular system, several human studies have concluded that, after controlling for reductions

OPEN ACCESS

Edited by:

Jacob Haus,

University of Michigan, United States

Reviewed by:

Sascha Goone,

University of Michigan, United States

Steven K. Malin,

University of Virginia, United States

*Correspondence:

Jason Hellmann

jason.Hellmann@louisville.edu

Specialty section:

This article was submitted to

Cardiovascular Metabolism,

a section of the journal

Frontiers in Cardiovascular Medicine

Received: 28 February 2019

Accepted: 10 May 2019

Published: 29 May 2019

Citation:

Chuong P, Wysoczynski M and Hellmann J (2019) Do Changes in

Innate Immunity Underlie the

Cardiovascular Benefits of Exercise?

Front. Cardiovasc. Med. 6:70.

doi: 10.3389/fcvm.2019.00070 in traditional CVD risk factors, the beneficial effects of regular exercise are attributable to a decrease in chronic inflammation and inflammatory mediator production $(1,5-8)$. These clinical findings are complemented by animal studies that report regular moderate intensity exercise decreases the risk for chronic disease development through modification of the immune system $(9,10)$. Despite the immunoregulatory effects of exercise, the underlying cellular mechanisms and signaling pathways that promote cardiovascular health remain unknown. Identifying key determinants by which exercise modulates inflammatory responses likely offer new therapeutic targets for the treatment of cardiovascular disease. Given that the innate immune system is responsible for initiating most inflammatory responses and causally contributes to cardiac pathology and repair, we have focused this opinion manuscript on the potential role of neutrophils and macrophages in mediating the cardioprotective effects afforded by exercise.

\section{EXERCISE-INDUCED CHANGES IN INNATE IMMUNITY}

Neutrophils are often referred to as the first responders of the acute inflammatory response. Following activation of the endothelium and edema formation, neutrophils diapedese predominantly at postcapillary venules- and emigrate to sites of injury along chemoattractant gradients of C5a, Il-1 $\beta, \mathrm{TNF} \alpha$, CXC chemokines (e.g., CXCL1, CXCL2, CXCL8), bioactive lipids such as leukotriene $\mathrm{B} 4\left(\mathrm{LTB}_{4}\right)$, and/or formylated bacteria-derived peptides. Upon phagocytosis and eradication of the inflammatory stimulus through NADPH oxidase activity, hypochlorous acid production, and/or neutralizing proteolytic enzymes, neutrophils undergo apoptosis (programmed cell death). This rapid and robust response is host protective, however in order to avoid secondary tissue damage and further propagation of the inflammatory response, apoptotic neutrophils are then cleared from the site of injury. Therefore, magnitude and duration of neutrophilic infiltration, phagocytic capacity, and subsequent apoptosis are critical factors that contribute to optimal healing. As such, mediators that prolong neutrophil survival including LPS, CRP, cyclin-dependent kinases, IL-8, GM-CSF and G-CSF delay neutrophil apoptosis and extend inflammatory responses $(11,12)$. 
Studies focused on understanding the effects of exercise training on neutrophil function and survival have produced differing results depending on exercise intensity and duration. After a single bout of high intensity exercise, leukocyte blood counts are dramatically elevated. This rapid response is attributed to demargination of neutrophils caused by increased shear stress and the actions of catecholamines in skeletal muscle vascular pools (13-15). Furthermore, a delayed or second wave of neutrophilia develops hours later through the actions of cortisol-induced bone marrow mobilization (16). This duration and intensity dependent increase in circulating neutrophils results in increased neutrophil extravasation into skeletal muscle tissue in response to exercise-induced injury (17). Interestingly, following a single bout of exercise, unstimulated neutrophil oxidative burst, phagocytosis, and degranulation are increased whereas degranulation and oxidative burst following an inflammatory challenge are decreased $(13,18)$. These findings suggests that repeated exercise training alter neutrophilic function to promote an overall anti-inflammatory effect upon inflammatory challenge (Figure 1). Given their established role in propagating the inflammatory cascade during atherogenesis and myocardial ischemia, anti-inflammatory modification of neutrophils following exercise training may contribute, in part, to the exercised-induced reduction in CVD risk. Nonetheless, future studies are needed to determine the optimal exercise duration and intensity needed to promote beneficial modifications of neutrophil survival and function for CVD risk reduction.

Macrophages perform important effector and accessory immune functions and are critical mediators in the host response to tissue damage and microbial insults. A trademark feature of macrophages is their ability to engulf foreign and dying bodies (e.g., macro = big, phage = eater; big eater). Tissue resident macrophages actively maintain tissue homeostasis by killing microbial invaders and by non-phlogistic clearance of millions of apoptotic cells that turnover daily (19). To perform these functions, macrophages retain phagocytic, cytotoxic and anti-tumor capabilities, all of which is altered in an exercise duration and intensity dependent manner. Furthermore, during an acute inflammatory response, macrophages play a critical role in initiating the resolution phase through the phagocytosis and removal of apoptotic neutrophils to prevent collateral tissue damage caused by secondary neutrophil necrosis (20). Along these lines, macrophages play a critical role in maintaining tissue function, regeneration, and homeostasis.

In addition to tissue resident macrophages, bone marrowderived circulating monocytes represent an immature form of macrophages, which can be rapidly recruited to sites of injury. In humans and mice, differing subsets of circulating monocytes have been described. One patrolling type of monocyte is thought to play endothelial supportive functions while another subset extravasate through the endothelium in response to inflammatory stimuli (21). This migratory process is accomplished through chemotactic gradients whereby monocytes are recruited into tissues in response to complement products, leukotrienes, IP-10, macrophage inflammatory protein (MIP), aggregated platelets, CCL2 (MCP-1), and/or CX3CL1 (fractalkine) (22). Following extravasation, monocytes mature into macrophages and, in

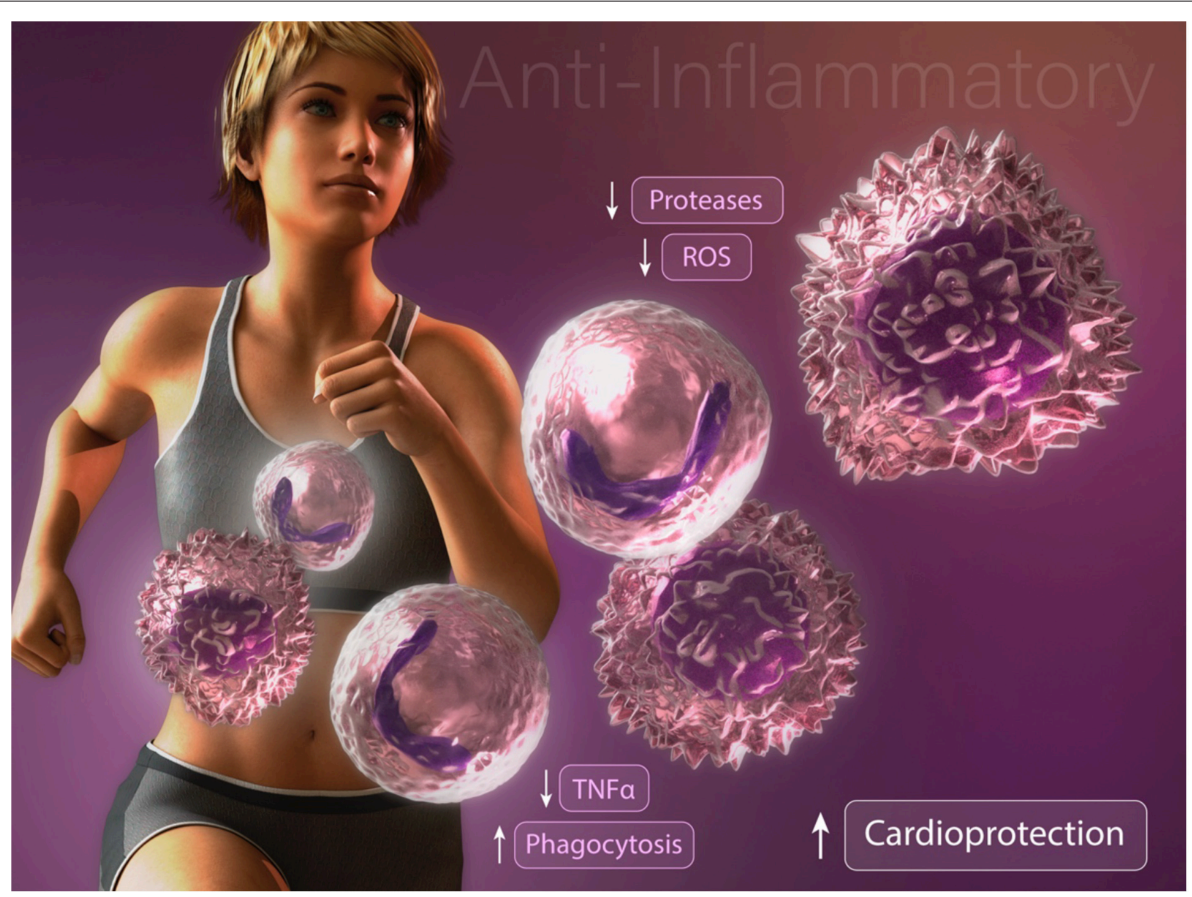

FIGURE 1 | Anti-inflammatory modifications of neutrophils and macrophages may contribute to exercise-enhanced cardioprotection. 
a broad sense, differentiate into classically (in response to inflammatory challenge) or alternatively activated (to enhance pro-resolving and tissue repair) macrophages according to local tissue micro-environment conditions (23). Pro-inflammatory stimuli cause macrophages to undergo a metabolic shift away from oxidative phosphorylation and toward glycolysis (24). Classically activated macrophages are characterized by the production of inflammatory cytokines, such as Il-1ß and TNF $\alpha$. Interestingly, inhibition of glycolysis using 2-deoxyglucose decreases LPS-stimulated inflammation in macrophages (25). Moreover, alternatively activated macrophages that secrete anti-inflammatory cytokines such as IL-10, rely on oxidative phosphorylation for energy production and display decreased expression of glycolytic enzymes (26).

Multiple studies have reported profound alterations in macrophage activation and function following exercise training. Consistent with an anti-inflammatory effect, high-fat diet fed mice subjected to exercise training display an enhanced proportion of alternatively activated macrophages in comparison with classically activated inflammatory macrophages in the adipose tissue (27). Furthermore, the authors report a reduction in the infiltration of inflammatory adipose tissue macrophages (27). Consistent with these findings, Kizaki et al. (28) reported that mice with free access to a running wheel have abrogated high fat diet-induced MCP-1, F4/80, and TNF $\alpha$ expression in adipose tissue. Importantly, these findings were recently supported in a human cohort study. Barry et al. (29) found that in the absence of weight loss, short-term moderate intensity, but not high-intensity, exercise training in obese adults resulted in down regulation of CCR2 and CXCR2 expression on circulating monocytes. Collectively, these results suggest that exercise training directly alters circulating monocytes and inhibits the infiltration of inflammatory monocyte/macrophages into adipose tissue. These data are intriguing given that inflammatory cytokine production from classically activated macrophages contributes to obesity-induced metabolic dysfunction of adipose tissue and systemic insulin resistance (30-32). These data provide one possible explanation by which exercise-induced changes promote an anti-inflammatory effect, however the underlying mechanisms remain unclear. Another possibility that may explain how exercise abrogates inflammation is found in studies assessing changes in macrophage phagocytic capacity (Figure 1). We have found that chronically inflamed obese diabetic mice display dysfunctional macrophage phagocytosis (33). Interestingly, promoting resolution of inflammation in these mice by restoring macrophage phagocytosis was associated with enhanced alternatively activated macrophage content in adipose tissue and decreased hyperglycemia, $(34,35)$ suggesting that dysfunctional macrophage phagocytosis may contribute to the development of insulin resistance. That exercise stimulates macrophage phagocytosis was reported several decades ago by Fehr et al $(36,37)$. They showed that a single bout of exhaustive endurance-running increased phagocytic activity of isolated human connective tissue macrophages and peritoneal macrophages. Others have documented an enhancement in rat peritoneal macrophage phagocytosis after just $5 \mathrm{~min}$ of exercise, consistent with the release of circulating factors and not alteration in phenotype (38). How duration, intensity, and diet impact exercise-induced changes in macrophage metabolic programming, phenotype, and function remains to be elucidated.

\section{ROLE OF INNATE IMMUNITY IN CARDIOVASCULAR DISEASE}

Acute cardiac ischemic events such as myocardial infarction (MI), trigger a sterile systemic inflammatory response that is required for the activation of the tissue healing program (39-41). For this, increased proliferation of the bone marrow hematopoietic stem/progenitor cells and activation of extramedullary hematopoiesis in the spleen generates a surplus of myeloid cells, mostly neutrophils and monocytes $(42,43)$. Secreted homing factors from the infarcted myocardium results in tissue recruitment of neutrophils and monocytes for the removal of necrotic tissue, initialization of angiogenesis, and stimulation of myofibroblasts for collagen synthesis and wound healing (41). This initial myocardial myeloid response is imperative for proper healing as interventions that result in a reduction of neutrophil or monocyte/macrophage infiltration, either through systemic depletion, splenectomy, or steroid treatment, impairs optimal post-MI healing and results in excessive fibrosis and possible cardiac rupture $(42,44)$. On the other hand, neutrophils and monocytes/macrophages secrete pro-inflammatory mediators including proteases and reactive oxygen species that in excess negatively affect tissue healing and contribute to myocardial damage. Therefore, overproduction of myeloid cells and excessive infiltration into the ischemic myocardium may result in inappropriate inflammation, compromised tissue integrity, and formation of a non-contracting scar that alters LV pump function (45). Conversely, rats subjected to exercise training prior to permanent coronary occlusion display a reduction in myocardial collagen deposition, cardiac deterioration, and mortality (46). Chronic inflammatory diseases, however, including atherosclerosis, hypertension, diet-induced obesity, and diabetes can further contribute to overproduction of myeloid cells and cause an imbalanced myeloid response following MI and sub-optimal infarct healing $(41,45)$. These findings illustrate the important role of innate immunity and proper inflammatory control following MI for optimal infarct healing.

Following MI and myocyte cell death, the myocardium is besieged by an intense inflammatory response that results in the formation of a collagen-based scar (40,41). A scar without contracting capabilities in the ischemic myocardium initiates left ventricular remodeling of the remote non-ischemic region of the myocardium, promoting hypertrophy, fibrosis, and progressive failure in pump function and the development of heart failure. Conversely, supervised exercise training in both men and women with chronic heart failure improves quality of life, reverses pathological cardiac remodeling, and decreases mortality and hospitalization above usual care (47). One of the hallmarks of patients with heart failure is chronic systemic inflammation (39-41). Pro-inflammatory cytokine levels, such as TNF $\alpha$ and IL-6, are closely associated with heart 
failure status, suggesting that inflammatory cytokine signaling contributes to progressive pump failure. Likewise, studies in mouse models of heart failure demonstrate that after MI, there is a chronically (4-8 weeks) active mononuclear phagocyte network remodeling that occurs in the spleen and non-ischemic regions of the heart $(48,49)$. Continuous accumulation of macrophages in the myocardium prompts progressive collagen deposition and impaired myocardial function. Inhibition of monocyte infiltration via blockade of adhesion molecules or splenectomy in mice with established heart failure dampens and improves adverse cardiac remodeling (48, 49). These findings highlight the detrimental role of an unregulated innate immune system in chronic heart failure. Interventions aimed at mitigating chronic inflammatory mediators in the post-MI myocardium offer improved outcomes in patients with ongoing pathological remodeling. Future studies are needed to determine the ideal exercise intensity and duration required for optimal cardiac remodeling.

A common cause of $\mathrm{MI}$ is rupture of vulnerable atherosclerotic plaques. Atherosclerosis is a chronic inflammatory disease characterized by the accumulation of lipids and leukocytes in the arterial wall. Similar to heart failure, monocytes are essential contributors to pathogenesis of the disease (50-54). Mice deficient in apolipoprotein E (ApoE KO) fed a Western style diet mobilize hematopoietic stem/progenitor cells from the bone marrow to extramedullary sites in the splenic red pulp, where they expand and differentiate to monocytes $(50,54,55)$. The surplus of splenic monocytes is released into the circulation where they adhere to the atherosclerotic endothelium and extravasate into lesions and differentiate into macrophages. As a consequence of abundant uptake of low-density lipoproteins, monocyte-derived macrophages transition into foam cells. Accumulation of foam cells in arterial walls is a hallmark of early atherosclerotic lesion formation (50, 52). Continuous accumulation of monocytes and their lineage descendant macrophages can contribute to fibrous cap thickening, hematoma, thrombi, calcification, and degeneration of plaque integrity. The relative abundance of macrophages in atherosclerotic plaques is regulated by their exit and/or death, but also sustained recruitment of monocytes. Efficient macrophage exit, or reduced monocyte recruitment, results in a reduction in lesional macrophage number and regression of disease. On the other hand, factors contributing to increased monocyte recruitment accelerate atherosclerosis $(56,57)$. As described above, acute $\mathrm{MI}$ increases bone marrow and splenic myelopoiesis in response to myocardial damage. However, overproduction of monocytes due to acute MI in mice with atherosclerosis results in increased monocyte recruitment, over production of pro-inflammatory cytokines and proteolytic enzymes in the atherosclerotic lesions which stimulates growth of arterial lesions and increased risk of plaque rupture (58). Exercise promotes cardiovascular health and reduces atherosclerotic lesion size and vulnerability. In both ApoE knockout and LDL receptor knockouts fed a western style diet, aerobic exercise training reduced early lesion size formation and enhanced lesion regression $(59,60)$. Moreover, exercise training in diabetic ApoE knockout animals resulted in improved glucose tolerance, lesion size, and plaque stability. Interestingly, these findings were associated with decreased lesional IL-6 levels and macrophage content (61). These data suggest that the anti-atherogenic effects of exercise may relate to changes in innate immunity.

Exercise has been a hallmark treatment strategy for uncontrolled and prolonged hypertension. Recent studies demonstrate that innate immunity is involved not only in end-organ damage due to hypertension, but also in the development of hypertension. Studies in mice with Csf1 gene mutation resulting in deficiency of various subtypes of macrophages, remain normotensive, and have reduced endothelial dysfunction and vascular remodeling after Ang II infusion or DOCA-salt treatment $(62,63)$. Similarly, systemic depletion of monocytes using a mouse model of lysozyme $\mathrm{M}$ driven expression of diphtheria toxin receptor results in resistance to Ang II induced hypertension, vascular dysfunction, cardiac hypertrophy, and oxidative stress $(64,65)$. These data suggest that monocytes/macrophages are involved in the etiology of hypertension, but the underlying mechanism has not been fully elucidated. Furthermore, monocytes/macrophages are also involved in hypertension-induced end-organ damage. Inhibition of CCR2 receptor in hypertensive mice reduced cardiac monocyte/macrophage infiltration and attenuated hypertrophy and fibrosis $(63,65)$. Thus, exercise-induced changes in innate immunity may play a protective role against the development of hypertension and end-organ damage.

\section{POTENTIAL ROLE OF SPECIALIZED PRO-RESOLVING MEDIATORS}

Given their profound anti-inflammatory and pro-resolving effects on innate immune cell cytokine production and function, it is intriguing to speculate on the potential role of specialized pro-resolving lipid mediators (SPMs) in the CVD risk reducing effect of exercise. We now know that the acute inflammatory response is composed of a resolution phase that is mediated, in part, by SPMs such as lipoxins (LX), resolvins (Rv), maresins $(\mathrm{MaR})$, protectins (PD), and the newly identified conjugates in tissue regeneration (e.g., RCTR, MCTR, and PCTR). SPMs are primarily synthesized from the enzymatic conversion (e.g., 5lipoxygenase, 12-lipoxygenase, and 15-lipoxygenase) of omega 3 -fatty acids and promote the resolution of inflammation by limiting excessive neutrophil infiltration, promoting apoptotic cell clearance, and enhancing overall host response (biosynthesis was recently reviewed $(66,67)$. Nevertheless, whether exercise affects resolution or the synthesis and actions of SPMs remains understudied. Future experiments are needed to evaluate whether systemic changes in molecular and cellular proresolving pathways contribute to the augmentation of innate immunity in exercise that contributes to its overall observed anti-inflammatory effect.

Produced largely by leukocytes, SPMs have been shown to have cardiovascular protective and reparative properties. Derived from EPA, RvE1 has been shown to have protective effects on cardiomyocytes and reduce infarct size in a dose dependent manner in a rat ischemia-reperfusion model (68). Additionally, 
RvD1 treatment reduced post-MI macrophage numbers and fibrosis resulting in a reduction in left ventricular dysfunction in mice (69). Moreover, SPMs RvE1, RvD1, RvD2, Mar1, and AT-LXA 4 have all been shown to prevent atheroprogression and enhance lesion stability in mouse models of atherosclerosis (7074). This exciting area of research will continue to uncover previously unknown basic mechanisms of sustained vascular inflammation and develop new therapeutic treatment options for atherosclerosis.

A limited amount of data does already exist that suggests exercise may stimulate the production of SPMs. Gangemi et al. (75) reported that urinary immunoreactive LXA $_{4}$ levels were elevated immediately and $24 \mathrm{~h}$ following a single bout of strenuous maximum intensity exercise in a small healthy human cohort. These were the only data until recently when Markworth et al. (76) using targeted metabololipidomics, reported peak serum levels of $\mathrm{LXA}_{4}$ and $\mathrm{LXB}_{4} 1 \mathrm{~h}$ post-exercise, with a transient elevation in RvE1. Interestingly, the authors further reported a sustained elevation of $\mathrm{RvD} 1$ and $\mathrm{PDx}$, a $\mathrm{PD} 1$ isomer, $24 \mathrm{~h}$ post-exercise training in humans. Consistent with these observations, Dalli et al. (77) also reported elevated plasma levels of RvD1, RvD2, and all four members of the newly identified 13-series n-3 DPA-derived resolvins, termed RvTs, in human peripheral blood samples following 30-45 min of vigorous intensity exercise. Moreover, DHA supplementation and exercise, stimulated human PBMCs to produce elevated levels of RvD1 in response to LPS. That RvD1 production is elevated in response to LPS above basal conditions following exercise was noted by the authors as a possible explanation for the overall antiinflammatory effect of exercise (78). Collectively, these results are consistent with the idea that exercise training represents a model of self-limited sterile inflammation that requires endogenous resolution programs for repair, however whether and if exercise training alters the magnitude and duration of inflammation resolution and SPM biosynthesis is unknown.

\section{FUTURE DIRECTION}

Several studies have evaluated the impact of exercise on circulating immune cell levels. Clinical studies have focused on understanding how exercise improves CVD outcomes by assessing changes in known inflammatory correlates of disease risk, including white blood cell count, IL-6, CRP, and other markers of haemostasis (e.g., fibrinogen) $(1,5,7,8,79)$. Furthermore, preclinical investigations have uncovered basic mechanisms by which regular exercise promotes an antiinflammatory immune response (9). Collectively, these studies have revealed that exercise reduces chronic inflammation and CVD by altering immune cell function and production of anti-inflammatory cytokines $(80,81)$. By describing changes in the abundance and inflammatory mediator production in circulating immune cell populations, these studies have advanced our knowledge by characterizing the anti-inflammatory effect of exercise; however questions regarding how diet and exercise intensity interact with beneficial changes in immunity remain largely unanswered. Mounting evidence suggests a critical role for SPMs in preventing or attenuating chronic cardiovascular inflammation [reviewed in (82)], however data regarding how exercise affects resolution biology is limited. We believe that future studies should continue to study changes in innate immune cell populations but that these investigations should be further expanded to incorporate assessments in cell function. A deeper understanding of how exercise alters immune cell function and the development and progression of CVD holds great therapeutic potential, especially for individuals who are often recalcitrant to exercise programs or those who could most benefit from exercise, but cannot, e.g., patients with advanced diabetes or heart failure (83-90).

\section{AUTHOR CONTRIBUTIONS}

All authors listed have made a substantial, direct and intellectual contribution to the work, and approved it for publication.

\section{FUNDING}

We acknowledge the support of NIH grants GM127495 (JH), HL141191 (MW), HL078825 (MW), and P20-RR024489

(Diabetes and Obesity Center).

\section{REFERENCES}

1. Mora S, Cook N, Buring JE, Ridker PM, Lee IM. Physical activity and reduced risk of cardiovascular events: potential mediating mechanisms. Circulation. (2007) 116:2110-8. doi: 10.1161/CIRCULATIONAHA.107.729939

2. Mandsager K, Harb S, Cremer P, Phelan D, Nissen SE, Jaber W. Association of cardiorespiratory fitness with long-term mortality among adults undergoing exercise treadmill testing. JAMA Netw Open. (2018) 1:e183605. doi: 10.1001/jamanetworkopen.2018.3605

3. Kohl HW III, Craig CL, Lambert EV, Inoue S, Alkandari JR, Leetongin G, et al. The pandemic of physical inactivity: global action for public health. Lancet. (2012) 380:294-305. doi: 10.1016/S0140-6736(12)60898-8

4. Ding D, Lawson KD, Kolbe-Alexander TL, Finkelstein EA, Katzmarzyk PT, van Mechelen W, et al. The economic burden of physical inactivity: a global analysis of major non-communicable diseases. Lancet. (2016) 388:1311-24. doi: 10.1016/S0140-6736(16)30383-X

5. Albert MA, Glynn RJ, Ridker PM. Effect of physical activity on serum C-reactive protein. Am J Cardiol. (2004) 93:221-5. doi: 10.1016/j.amjcard.2003.09.046

6. Borodulin K, Laatikainen T, Salomaa V, Jousilahti P. Associations of leisure time physical activity, self-rated physical fitness, and estimated aerobic fitness with serum C-reactive protein among 3,803 adults. Atherosclerosis. (2006) 185:381-7. doi: 10.1016/j.atherosclerosis.2005.06.015

7. Autenrieth CS, Baumert J, Baumeister SE, Fischer B, Peters A, Doring A, et al. Association between domains of physical activity and all-cause, cardiovascular and cancer mortality. Eur J Epidemiol. (2011) 26:91-9. doi: 10.1007/s10654-010-9517-6

8. Villegas R, Xiang YB, Cai H, Elasy T, Cai Q, Zhang X, et al. Lifestyle determinants of C-reactive protein in middle-aged, urban Chinese men. Nutr Metab Cardiovasc Dis. (2012) 22:223-30. doi: 10.1016/j.numecd.2010.07.007

9. Petersen AM, Pedersen BK. The anti-inflammatory effect of exercise. J Appl Physiol. (2005) 98:1154-62. doi: 10.1152/japplphysiol.00164.2004 
10. Gleeson M, Bishop NC, Stensel DJ, Lindley MR, Mastana SS, Nimmo MA. The anti-inflammatory effects of exercise: mechanisms and implications for the prevention and treatment of disease. Nat Rev Immunol. (2011) 11:607-15. doi: $10.1038 /$ nri3041

11. Filep JG, El Kebir D. Neutrophil apoptosis: a target for enhancing the resolution of inflammation. J Cell Biochem. (2009) 108:1039-46. doi: $10.1002 /$ jcb. 22351

12. Fox S, Leitch AE, Duffin R, Haslett C, Rossi AG. Neutrophil apoptosis: relevance to the innate immune response and inflammatory disease. J Innate Immun. (2010) 2:216-27. doi: 10.1159/000284367

13. Robson PJ, Blannin AK, Walsh NP, Castell LM, Gleeson M. Effects of exercise intensity, duration and recovery on in vitro neutrophil function in male athletes. Int J Sports Med. (1999) 20:128-35. doi: 10.1055/s-2007-971106

14. Morozov VI, Pryatkin SA, Kalinski MI, Rogozkin VA. Effect of exercise to exhaustion on myeloperoxidase and lysozyme release from blood neutrophils. Eur J Appl Physiol. (2003) 89:257-62. doi: 10.1007/s00421-002-0755-5

15. Mochida N, Umeda T, Yamamoto Y, Tanabe M, Kojima A, Sugawara K, et al. The main neutrophil and neutrophil-related functions may compensate for each other following exercise-a finding from training in university judoists. Luminescence. (2007) 22:20-8. doi: 10.1002/bio.922

16. Pyne DB. Regulation of neutrophil function during exercise. Sports Med. (1994) 17:245-58.

17. Nunes-Silva A, Bernardes PT, Rezende BM, Lopes F, Gomes EC, Marques PE, et al. Treadmill exercise induces neutrophil recruitment into muscle tissue in a reactive oxygen species-dependent manner. An intravital microscopy study PLoS ONE. (2014) 9:e96464. doi: 10.1371/journal.pone.0096464

18. Peake JM. Exercise-induced alterations in neutrophil degranulation and respiratory burst activity: possible mechanisms of action. Exerc Immunol Rev. (2002) 8:49-100.

19. Ren Y, Savill J. Apoptosis: the importance of being eaten. Cell Death Differ. (1998) 5:563-8. doi: 10.1038/sj.cdd.4400407

20. Ortega-Gomez A, Perretti M, Soehnlein O. Resolution of inflammation: an integrated view. EMBO Mol Med. (2013) 5:661-74. doi: $10.1002 / \mathrm{emmm} .201202382$

21. Geissmann F, Jung S, Littman DR. Blood monocytes consist of two principal subsets with distinct migratory properties. Immunity. (2003) 19:71-82. doi: 10.1016/s1074-7613(03)00174-2

22. Shi C, Pamer EG. Monocyte recruitment during infection and inflammation. Nat Rev Immunol. (2011) 11:762-74. doi: 10.1038/nri3070

23. Martinez FO, Gordon S. The M1 and M2 paradigm of macrophage activation: time for reassessment. F1000Prime Rep. (2014) 6:13. doi: 10.12703/P6-13

24. Kelly B, O’Neill LA. Metabolic reprogramming in macrophages and dendritic cells in innate immunity. Cell Res. (2015) 25:771-84. doi: 10.1038/cr.2015.68

25. Kellett DN. 2-Deoxyglucose and inflammation. J Pharm Pharmacol. (1966) 18:199-200.

26. Galvan-Pena S, O'Neill LA. Metabolic reprograming in macrophage polarization. Front Immunol. (2014) 5:420. doi: 10.3389/fimmu.2014.00420

27. Kawanishi N, Yano H, Yokogawa Y, Suzuki K. Exercise training inhibits inflammation in adipose tissue via both suppression of macrophage infiltration and acceleration of phenotypic switching from M1 to M2 macrophages in high-fat-diet-induced obese mice. Exerc Immunol Rev. (2010) 16:105-18.

28. Kizaki T, Maegawa T, Sakurai T, Ogasawara JE, Ookawara T, Oh-ishi S, et al. Voluntary exercise attenuates obesity-associated inflammation through ghrelin expressed in macrophages. Biochem Biophys Res Commun. (2011) 413:454-9. doi: 10.1016/j.bbrc.2011.08.117

29. Barry JC, Simtchouk S, Durrer C, Jung ME, Little JP. Short-term exercise training alters leukocyte chemokine receptors in obese adults. Med Sci Sports Exerc. (2017) 49:1631-40. doi: 10.1249/MSS.0000000000001261

30. Hotamisligil GS, Shargill NS, Spiegelman BM. Adipose expression of tumor necrosis factor-alpha: direct role in obesity-linked insulin resistance. Science. (1993) 259:87-91.

31. Ventre J, Doebber T, Wu M, MacNaul K, Stevens K, Pasparakis M, et al. Targeted disruption of the tumor necrosis factor-alpha gene: metabolic consequences in obese and nonobese mice. Diabetes. (1997) 46:1526-31.

32. Uysal KT, Wiesbrock SM, Marino MW, Hotamisligil GS. Protection from obesity-induced insulin resistance in mice lacking TNF-alpha function. Nature. (1997) 389:610-4. doi: 10.1038/39335
33. Tang Y, Zhang MJ, Hellmann J, Kosuri M, Bhatnagar A, Spite M. Proresolution therapy for the treatment of delayed healing of diabetic wounds. Diabetes. (2013) 62:618-27. doi: 10.2337/db12-0684

34. Hellmann J, Tang Y, Kosuri M, Bhatnagar A, Spite M. Resolvin D1 decreases adipose tissue macrophage accumulation and improves insulin sensitivity in obese-diabetic mice. FASEB J. (2011) 25:2399-407. doi: 10.1096/fj.10-178657

35. Hellmann J, Zhang MJ, Tang Y, Rane M, Bhatnagar A, Spite M. Increased saturated fatty acids in obesity alter resolution of inflammation in part by stimulating prostaglandin production. J Immunol. (2013) 191:1383-92. doi: 10.4049/jimmunol.1203369

36. Fehr HG, Lotzerich $\mathrm{H}$, Michna $\mathrm{H}$. The influence of physical exercise on peritoneal macrophage functions: histochemical and phagocytic studies. Int J Sports Med. (1988) 9:77-81. doi: 10.1055/s-2007-1024983

37. Fehr HG, Lotzerich $\mathrm{H}$, Michna $\mathrm{H}$. Human macrophage function and physical exercise: phagocytic and histochemical studies. Eur J Appl Physiol Occup Physiol. (1989) 58:613-7.

38. Ferreira CK, Prestes J, Donatto FF, Verlengia R, Navalta JW, Cavaglieri CR. Phagocytic responses of peritoneal macrophages and neutrophils are different in rats following prolonged exercise. Clinics. (2010) 65:1167-73. doi: 10.1590/s1807-59322010001100020

39. Frangogiannis NG. Inflammation in cardiac injury, repair and regeneration. Curr Opin Cardiol. (2015) 30:240-5. doi: 10.1097/HCO.0000000000000158

40. Frangogiannis NG. Pathophysiology of myocardial infarction. Compr Physiol. (2015) 5:1841-75. doi: 10.1002/cphy.c150006

41. Prabhu SD, Frangogiannis NG. The biological basis for cardiac repair after myocardial infarction: from inflammation to fibrosis. Circ Res. (2016) 119:91112. doi: 10.1161/CIRCRESAHA.116.303577

42. Heidt T, Courties G, Dutta P, Sager HB, Sebas M, Iwamoto Y, et al. Differential contribution of monocytes to heart macrophages in steadystate and after myocardial infarction. Circ Res. (2014) 115:284-95. doi: 10.1161/CIRCRESAHA.115.303567

43. Heidt T, Sager HB, Courties G, Dutta P, Iwamoto Y, Zaltsman A, et al. Chronic variable stress activates hematopoietic stem cells. Nat Med. (2014) 20:754-8. doi: $10.1038 / \mathrm{nm} .3589$

44. Horckmans M, Ring L, Duchene J, Santovito D, Schloss MJ, Drechsler M, et al. Neutrophils orchestrate post-myocardial infarction healing by polarizing macrophages towards a reparative phenotype. Eur Heart J. (2017) 38:187-97. doi: 10.1093/eurheartj/ehw002

45. Nahrendorf M, Pittet MJ, Swirski FK. Monocytes: protagonists of infarct inflammation and repair after myocardial infarction. Circulation. (2010) 121:2437-45. doi: 10.1161/CIRCULATIONAHA.109.916346

46. Bozi LH, Maldonado IR, Baldo MP, Silva MF, Moreira JB, Novaes RD, et al. Exercise training prior to myocardial infarction attenuates cardiac deterioration and cardiomyocyte dysfunction in rats. Clinics. (2013) 68:54956. doi: 10.6061/clinics/2013(04)18

47. O'Connor CM, Whellan DJ, Lee KL, Keteyian SJ, Cooper LS, Ellis SJ, et al. Efficacy and safety of exercise training in patients with chronic heart failure: HF-ACTION randomized controlled trial. JAMA. (2009) 301:1439-50. doi: 10.1001/jama.2009.454

48. Ismahil MA, Hamid T, Bansal SS, Patel B, Kingery JR, Prabhu SD. Remodeling of the mononuclear phagocyte network underlies chronic inflammation and disease progression in heart failure: critical importance of the cardiosplenic axis. Circ Res. (2014) 114:266-82. doi: 10.1161/CIRCRESAHA.113.301720

49. Sager HB, Hulsmans M, Lavine KJ, Moreira MB, Heidt T, Courties G, et al. Proliferation and recruitment contribute to myocardial macrophage expansion in chronic heart failure. Circ Res. (2016) 119:853-64. doi: 10.1161/CIRCRESAHA.116.309001

50. Swirski FK, Nahrendorf M. Leukocyte behavior in atherosclerosis, myocardial infarction, and heart failure. Science. (2013) 339:161-6. doi: $10.1126 /$ science. 1230719

51. Nahrendorf M, Swirski FK. Immunology. Neutrophil-macrophage communication in inflammation and atherosclerosis Science. (2015) 349:237-8. doi: 10.1126/science.aac7801

52. Swirski FK, Nahrendorf M, Libby P. Mechanisms of myeloid cell modulation of atherosclerosis. Microbiol Spectr. (2016) 4:2015. doi: 10.1128/microbiolspec.MCHD-0026-2015

53. Nahrendorf M, Swirski FK. Cholesterol, CCR2, and monocyte phenotypes in atherosclerosis. Eur Heart J. (2017) 38:1594-6. doi: 10.1093/eurheartj/ehx098 
54. van der Valk FM, Kuijk C, Verweij SL, Stiekema LCA, Kaiser Y, Zeerleder S, et al. Increased haematopoietic activity in patients with atherosclerosis. Eur Heart J. (2017) 38:425-32. doi: 10.1093/eurheartj/ehw246

55. Robbins CS, Chudnovskiy A, Rauch PJ, Figueiredo JL, Iwamoto Y, Gorbatov R, et al. Extramedullary hematopoiesis generates Ly-6C(high) monocytes that infiltrate atherosclerotic lesions. Circulation. (2012) 125:36474. doi: 10.1161/CIRCULATIONAHA.111.061986

56. Feig JE, Pineda-Torra I, Sanson M, Bradley MN, Vengrenyuk Y, Bogunovic $\mathrm{D}$, et al. LXR promotes the maximal egress of monocyte-derived cells from mouse aortic plaques during atherosclerosis regression. J Clin Invest. (2010) 120:4415-24. doi: 10.1172/JCI38911

57. Potteaux S, Gautier EL, Hutchison SB, van Rooijen N, Rader DJ, Thomas $\mathrm{MJ}$, et al. Suppressed monocyte recruitment drives macrophage removal from atherosclerotic plaques of Apoe-/- mice during disease regression. J Clin Invest. (2011) 121:2025-36. doi: 10.1172/JCI43802

58. Dutta P, Courties G, Wei Y, Leuschner F, Gorbatov R, Robbins CS, et al. Myocardial infarction accelerates atherosclerosis. Nature. (2012) 487:325-9. doi: $10.1038 /$ nature 11260

59. Ramachandran S, Penumetcha M, Merchant NK, Santanam N, Rong R, Parthasarathy S. Exercise reduces preexisting atherosclerotic lesions in LDL receptor knock out mice. Atherosclerosis. (2005) 178:33-8. doi: 10.1016/j.atherosclerosis.2004.08.010

60. Jakic B, Carlsson M, Buszko M, Cappellano G, Ploner C, Onestingel E, et al. The effects of endurance exercise and diet on atherosclerosis in young and aged ApoE-/- and wild-type mice. Gerontology. (2019) 65:45-56. doi: 10.1159/000492571

61. Kadoglou NP, Moustardas P, Kapelouzou A, Katsimpoulas M, Giagini A, Dede E, et al. The anti-inflammatory effects of exercise training promote atherosclerotic plaque stabilization in apolipoprotein E knockout mice with diabetic atherosclerosis. Eur J Histochem. (2013) 57:e3. doi: 10.4081/ejh.2013.e3

62. Ko EA, Amiri F, Pandey NR, Javeshghani D, Leibovitz E, Touyz RM, et al. Resistance artery remodeling in deoxycorticosterone acetate-salt hypertension is dependent on vascular inflammation: evidence from m-CSFdeficient mice. Am J Physiol Heart Circ Physiol. (2007) 292:H1789-1795. doi: 10.1152/ajpheart.01118.2006

63. Wenzel U, Turner JE, Krebs C, Kurts C, Harrison DG, Ehmke H. Immune mechanisms in arterial hypertension. J Am Soc Nephrol. (2016) 27:677-86. doi: 10.1681/ASN.2015050562

64. Wenzel P, Knorr M, Kossmann S, Stratmann J, Hausding M, Schuhmacher $\mathrm{S}$, et al. Lysozyme M-positive monocytes mediate angiotensin II-induced arterial hypertension and vascular dysfunction. Circulation. (2011) 124:137081. doi: 10.1161/CIRCULATIONAHA.111.034470

65. Wenzel P. Monocytes as immune targets in arterial hypertension. $\mathrm{Br} J$ Pharmacol. (2019) 176:1966-77. doi: 10.1111/bph.14389

66. Bannenberg GL, Chiang N, Ariel A, Arita M, Tjonahen E, Gotlinger KH, et al. Molecular circuits of resolution: formation and actions of resolvins and protectins. J Immunol. (2005) 174:4345-55. doi: 10.4049/jimmunol.174.7.4345

67. Chiang N, Serhan CN. Structural elucidation and physiologic functions of specialized pro-resolving mediators and their receptors. Mol Aspects Med. (2017) 58:114-29. doi: 10.1016/j.mam.2017.03.005

68. Keyes KT, Ye Y, Lin Y, Zhang C, Perez-Polo JR, Gjorstrup P, et al. Resolvin E1 protects the rat heart against reperfusion injury. Am J Physiol Heart Circ Physiol. (2010) 299:H153-64. doi: 10.1152/ajpheart.01057.2009

69. Kain V, Ingle KA, Colas RA, Dalli J, Prabhu SD, Serhan CN, et al. Resolvin D1 activates the inflammation resolving response at splenic and ventricular site following myocardial infarction leading to improved ventricular function. J Mol Cell Cardiol. (2015) 84:24-35. doi: 10.1016/j.yjmcc.2015.04.003

70. Hasturk H, Abdallah R, Kantarci A, Nguyen D, Giordano N, Hamilton J, et al. Resolvin E1 (RvE1) attenuates atherosclerotic plaque formation in diet and inflammation-induced atherogenesis. Arterioscler Thromb Vasc Biol. (2015) 35:1123-33. doi: 10.1161/ATVBAHA.115.305324

71. Fredman G, Hellmann J, Proto JD, Kuriakose G, Colas RA, Dorweiler B, et al. An imbalance between specialized pro-resolving lipid mediators and proinflammatory leukotrienes promotes instability of atherosclerotic plaques. Nat Commun. (2016) 7:12859. doi: 10.1038/ncomms12859

72. Salic K, Morrison MC, Verschuren L, Wielinga PY, Wu LJ, Kleemann R, et al. Resolvin E1 attenuates atherosclerosis in absence of cholesterol-lowering effects and on top of atorvastatin. Atherosclerosis. (2016) 250:158-65. doi: 10.1016/j.atherosclerosis.2016.05.001
73. Viola JR, Lemnitzer P, Jansen Y, Csaba G, Winter C, Neideck C, et al. Resolving lipid mediators maresin 1 and resolvin D2 prevent atheroprogression in mice. Circ Res. (2016) 119:1030-8. doi: 10.1161/CIRCRESAHA.116.309492

74. Petri MH, Laguna-Fernandez A, Arnardottir H, Wheelock CE, Perretti M, Hansson GK, et al. Aspirin-triggered lipoxin A4 inhibits atherosclerosis progression in apolipoprotein E-/- mice. Br J Pharmacol. (2017) 174:4043-54. doi: $10.1111 /$ bph.13707

75. Gangemi S, Luciotti G, D’Urbano E, Mallamace A, Santoro D, Bellinghieri G, et al. Physical exercise increases urinary excretion of lipoxin A4 and related compounds. J Appl Physiol. (2003) 94:2237-40. doi: 10.1152/japplphysiol.01004.2002

76. Markworth JF, Vella L, Lingard BS, Tull DL, Rupasinghe TW, Sinclair AJ, et al. Human inflammatory and resolving lipid mediator responses to resistance exercise and ibuprofen treatment. Am J Physiol Regul Integr Comp Physiol. (2013) 305:R1281-96. doi: 10.1152/ajpregu.00128.2013

77. Dalli J, Chiang N, Serhan CN. Elucidation of novel 13-series resolvins that increase with atorvastatin and clear infections. Nat Med. (2015) 21:1071-5. doi: $10.1038 / \mathrm{nm} .3911$

78. Capo X, Martorell M, Sureda A, Tur JA, Pons A. Effects of dietary Docosahexaenoic, training and acute exercise on lipid mediators. J Int Soc Sports Nutr. (2016) 13:16. doi: 10.1186/s12970-016-0126-y

79. Slentz CA, Houmard JA, Kraus WE. Modest exercise prevents the progressive disease associated with physical inactivity. Exerc Sport Sci Rev. (2007) 35:1823. doi: 10.1249/01.jes.0000240019.07502.01

80. Flynn MG, McFarlin BK. Toll-like receptor 4: link to the antiinflammatory effects of exercise? Exerc Sport Sci Rev. (2006) 34:176-81. doi: 10.1249/01.jes.0000240027.22749.14

81. Pedersen BK, Febbraio MA. Muscle as an endocrine organ: focus on muscle-derived interleukin-6. Physiol Rev. (2008) 88:1379-406. doi: 10.1152/physrev.90100.2007

82. Sansbury BE, Spite M. Resolution of acute inflammation and the role of resolvins in immunity, thrombosis, and vascular biology. Circ Res. (2016) 119:113-30. doi: 10.1161/CIRCRESAHA.116.307308

83. Allen FM, Stillman E, Fitz R. Total Dietary Regulation in the Treatment of Diabetes. New York, NY: The Rockefeller Institute for Medical Research (1919).

84. Hetzel KS. Muscular exercise in diabetes mellitus. Br Med J. (1925) 1:102-6.

85. Lawrence RD. The Diabetic Life. Philadelphia, PA: P. Blakiston's Son \& Co (1925).

86. Bajpeyi S, Tanner CJ, Slentz CA, Duscha BD, McCartney JS, Hickner RC, et al. Effect of exercise intensity and volume on persistence of insulin sensitivity during training cessation. J Appl Physiol. (2009) 106:1079-85. doi: 10.1152/japplphysiol.91262.2008

87. Church TS, Blair SN, Cocreham S, Johannsen N, Johnson W, Kramer K, et al. Effects of aerobic and resistance training on hemoglobin A1c levels in patients with type 2 diabetes: a randomized controlled trial. JAMA. (2010) 304:2253-62. doi: 10.1001/jama.2010.1710

88. Bouchard C, Blair SN, Church TS, Earnest CP, Hagberg JM, Hakkinen K, et al. Adverse metabolic response to regular exercise: is it a rare or common occurrence? PLoS ONE. (2012) 7:e37887. doi: 10.1371/journal.pone.00 37887

89. Sparks LM, Johannsen NM, Church TS, Earnest CP, Moonen-Kornips E, Moro C, et al. Nine months of combined training improves ex vivo skeletal muscle metabolism in individuals with type 2 diabetes. J Clin Endocrinol Metab. (2013) 98:1694-702. doi: 10.1210/jc.2012-3874

90. Stephens NA, Sparks LM. Resistance to the beneficial effects of exercise in type 2 diabetes: are some individuals programmed to fail? J Clin Endocrinol Metab. (2015) 100:43-52. doi: 10.1210/jc.2014-2545

Conflict of Interest Statement: The authors declare that the research was conducted in the absence of any commercial or financial relationships that could be construed as a potential conflict of interest.

Copyright (C) 2019 Chuong, Wysoczynski and Hellmann. This is an open-access article distributed under the terms of the Creative Commons Attribution License (CC $B Y)$. The use, distribution or reproduction in other forums is permitted, provided the original author(s) and the copyright owner(s) are credited and that the original publication in this journal is cited, in accordance with accepted academic practice. No use, distribution or reproduction is permitted which does not comply with these terms. 